\title{
ANTIOXIDANTES DIETÉTICOS: CONTROVÉRSIAS E PERSPECTIVAS
}

Fernanda Menezes Cerqueira*, Marisa Helena Gennari de Medeiros e Ohara Augusto

Departamento de Bioquímica, Instituto de Química, Universidade de São Paulo, CP 26077, 05513-970 São Paulo - SP, Brasil

Recebido em 10/10/05; aceito em 20/4/06; publicado na web em 10/1/07

\begin{abstract}
DIETETIC ANTIOXIDANTS: CONTROVERSIES AND PERSPECTIVES The generation of reactive oxygen and nitrogen species (ROS and RNS) during metabolism is capable of damaging cellular biomolecules. To be protected against oxidative injury, cells evolved complex cellular defense mechanisms and the capability to use exogenous antioxidants to eliminate ROS/RNS. The potential role of micronutrients as antioxidants (vitamin C, vitamin E, carotenoids and poliphenols) has stimulated intense research efforts. In various human supplementation studies, however, these compounds presented pro-oxidant effects at high doses for most risk groups. Therefore, more studies about the bioavailability, tissue uptake, metabolism and biological activities should be performed before establishing recommendations for disease prevention.
\end{abstract}

Keywords: antioxidant vitamins; carotenoids; poliphenols.

\section{INTRODUÇÃO}

Os organismos vivos interagem com o meio ambiente visando manter um ambiente interno que favoreça a sobrevivência, o crescimento e a reprodução. $\mathrm{O}$ oxigênio molecular $\left(\mathrm{O}_{2}\right)$ obtido da atmosfera é vital para organismos aeróbios; contudo, espécies reativas formadas intracelularmente a partir do oxigênio ameaçam a integridade celular por meio da oxidação de biomoléculas, e podem comprometer processos biológicos importantes ${ }^{1}$.

O dano oxidativo de biomoléculas pode levar à inativação enzimática, mutação, ruptura de membrana, ao aumento na aterogenicidade de lipoproteínas plasmáticas de baixa densidade e à morte celular. Estes efeitos tóxicos do oxigênio têm sido associados ao envelhecimento e ao desenvolvimento de doenças crônicas, inflamatórias e degenerativas ${ }^{2}$.

A despeito deste paradoxo, a vida aeróbia tornou-se possível graças às adaptações biológicas que levaram ao desenvolvimento de defesas antioxidantes contra a toxicidade do oxigênio e espécies derivadas deste. As adaptações biológicas às mudanças do meio ambiente guiam o processo evolutivo. Neste sentido, as adaptações podem ser definidas como características que se tornam aumentadas e mantidas sob seleção ${ }^{1}$.

Embora as defesas antioxidantes endógenas sejam efetivas, não são infalíveis, e constantemente há formação de espécies reativas de oxigênio e de nitrogênio (ROS/RNS) que interagem em diferentes níveis com o ambiente celular antes de serem eliminadas, o que, à primeira vista, pode parecer uma falha evolutiva. Todavia, há evidências recentes de que um certo nível destas espécies é imprescindível para muitas funções fisiológicas. Por ex., o enovelamento de proteínas nascentes no retículo endoplasmático ocorre em um meio mais oxidante que o restante da célula para a formação de pontes dissulfeto ${ }^{1}$. Também, muitos genes são transcritos após oxidação transitória e baixas concentrações de alguns oxidantes estimulam a proliferação celular, como exemplificado pela adição de $1 \mu \mathrm{M}$ de $\mathrm{H}_{2} \mathrm{O}_{2}$ à cultura de células ${ }^{3}$.

Os componentes celulares não são protegidos totalmente por antioxidantes endógenos, e é bem estabelecido que antioxidantes obtidos da dieta são indispensáveis para a defesa apropriada contra

*e-mail: fernandamcerqueira@yahoo.com.br oxidação e, portanto, têm importante papel na manutenção da saúde. Os incontestáveis benefícios para a saúde associados ao consumo de frutas e hortaliças devem-se, em parte, à presença de antioxidantes nestes alimentos ${ }^{4}$.

Os mecanismos de ação antioxidante de ácido ascórbico e $\alpha$ tocoferol in vitro são conhecidos. Além destes, os carotenóides e polifenóis estão sendo estudados, procurando-se estabelecer suas eficiências de absorção no trato gastrointestinal, biodisponibilidades, mecanismos de ação e recomendações para consumo humano. Há perspectivas de que antioxidantes dietéticos possam ser usados futuramente no tratamento de doenças cuja gênese envolva processos oxidativos, mas os efeitos protetores de dietas saudáveis como a mediterrânea, por ex., não parecem ser reproduzidos por meio do uso de suplementos nutricionais ${ }^{1}$.

\section{PRÓ-OXIDANTES VERSUS ANTIOXIDANTES}

Pró-oxidantes são substâncias endógenas ou exógenas que possuem a capacidade de oxidar moléculas-alvo. Radicais livres são espécies cuja reatividade resulta da presença de um ou mais elétrons desemparelhados na estrutura atômica, capazes de existência independente em intervalos de tempo variáveis ${ }^{5}$.

Espécies reativas de oxigênio (ROS) e espécies reativas de nitrogênio (RNS) são termos que abrangem todas as formas reativas do oxigênio e nitrogênio, incluindo radicais e não-radicais que participam da iniciação e progressão das reações em cadeia envolvendo a formação de espécies radicalares. A reatividade destes compostos com biomoléculas é variável, sendo alguns estáveis e pouco reativos, como por ex. o radical superóxido, $\mathrm{O}_{2}^{*-}\left(\mathrm{k}=10^{1} \mathrm{M}^{-1} \mathrm{~s}^{-1}\right)$ e outros altamente reativos, apresentando velocidade de reação próxima à constante de colisão com moléculas-alvo, sendo o radical hidroxila, $\mathrm{HO}$; o principal exemplo $\left(\mathrm{k} \sim 10^{9} \mathrm{M}^{-1} \mathrm{~s}^{-1}\right)$. Embora ROS/RNS sejam associadas à oxidação, algumas são agentes redutores em meio biológico, mas também contribuem para reações em cadeia que convergem para dano em biomoléculas ${ }^{2}$. Os principais tipos de reações que envolvem radicais livres estão sumarizados na Figura 1.

As reações de eliminação de radicais livres (Equações 1 a 6) não são favorecidas em condições fisiológicas normais, devido às suas baixas concentrações. Assim, a principal forma de eliminação destas espécies e, portanto, da interrupção de reações em cadeias propagadas 


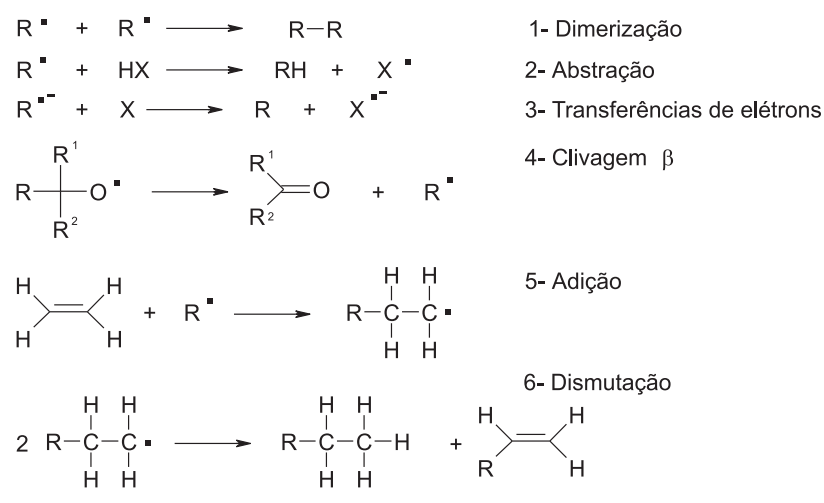

Figura 1. Principais tipos de reações radicalares. Reproduzida da ref. 6 , com permissão da SBPC

por elas depende da ação de compostos denominados antioxidantes ${ }^{6}$.

$\mathrm{O}$ próprio $\mathrm{O}_{2}$ no estado fundamental é um radical, uma vez que contém 2 elétrons desemparelhados no último orbital molecular. Todavia, o oxigênio reage lentamente com compostos que não possuam elétrons desemparelhados $\left(\mathrm{k}<10^{1} \mathrm{M}^{-1} \mathrm{~s}^{-1}\right)$, ou seja, não reage com a maioria dos componentes celulares. Entretanto, a reação de $\mathrm{O}_{2}$ com íons de metais de transição e radicais livres resulta em uma variedade de ROS/RNS, que podem efetivamente iniciar reações em cadeia e atacar biomoléculas ${ }^{2}$. Estima-se que cerca de $0,1 \%$ do $\mathrm{O}_{2}$ utilizado durante a respiração mitocondrial forma ROS, devido ao escape dos elétrons dos complexos que compõem a cadeia respiratória (Figura 2).

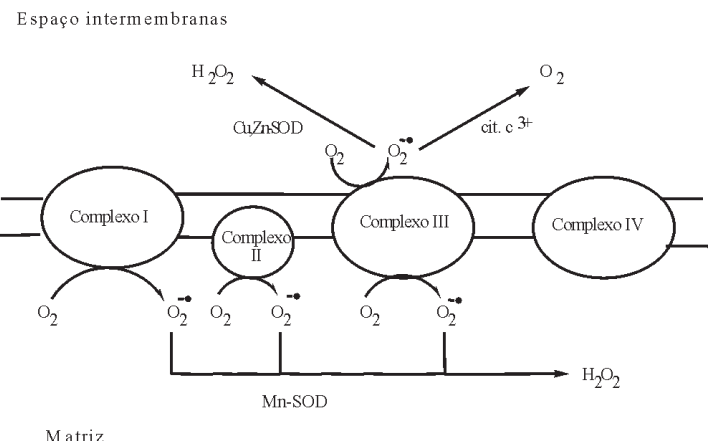

Figura 2. Formação de radicais livres na cadeia de transporte de elétrons mitocondrial

Além da cadeia de transporte de elétrons mitocondrial, ROS/ RNS também são produzidas endogenamente por vários sistemas enzimáticos e células do sistema imune, além de serem formadas a partir da exposição à radiação ionizante ${ }^{7}$.

Embora certo nível de ROS e RNS esteja envolvido na regulação de processos fisiológicos, o excesso na produção destes compostos leva à superestimulação de algumas vias intracelulares, o que geralmente está associado ao aparecimento de diversas doenças (Figura 3). Além disso, a própria natureza reativa destas espécies leva a modificações em biomoléculas, provocando alterações em suas estruturas e funções. Entre as alterações mais drásticas encontram-se alterações na ribose e bases nitrogenadas do DNA (ácido desoxirribonucléico); ligações cruzadas entre bases nitrogenadas, DNA e proteínas e proteína-proteína; formação de adutos ${ }^{8}$; peroxidação de PUFAs (ácidos graxos poliinsaturados) que compõem membranas plasmáticas e lipoproteínas ${ }^{9}$ e nitração ${ }^{10}$ e nitrosilação de proteínas $^{11}$.

Em vista dos prejuízos provenientes do excesso de ROS e RNS, as células dispõem de uma variedade de mecanismos de defesa con-

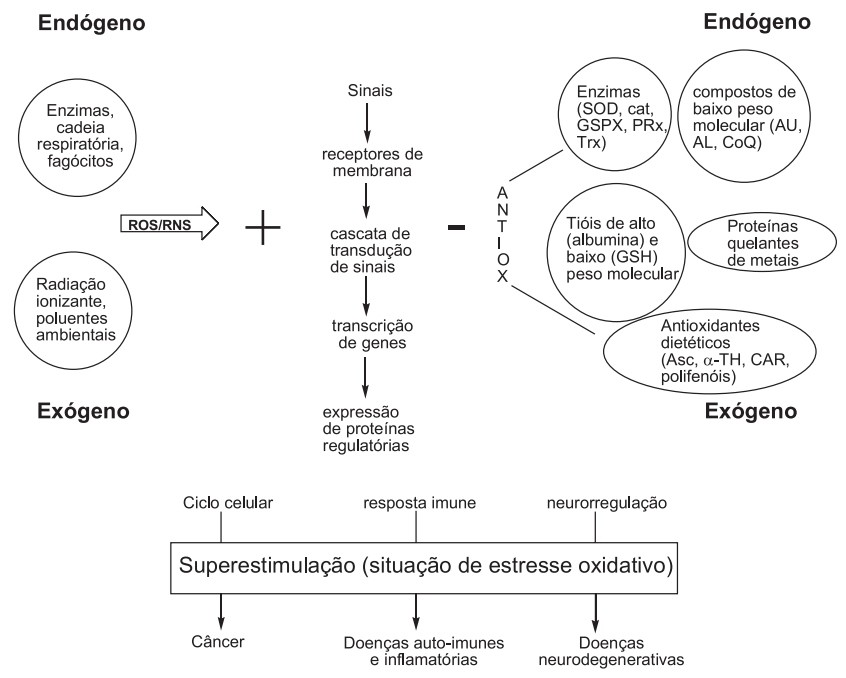

Figura 3. Esquema demonstrativo de regulação fisiológica modulada pelo estado redox intracelular. As espécies oxidantes (ROS/RNS) geralmente se relacionam à estimulação da expressão de proteínas - envolvidas no controle de importantes processos fisiológicos (ciclo celular, resposta imune e neuroregulação). As espécies antioxidantes modulariam negativamente tais funções. $O$ desequilíbrio entre as modulações positiva e negativa levaria ao aparecimento de doenças. Os antioxidantes (ANTIOX) endógenos incluem enzimas: superóxido dismutase (SOD), catalase (CAT), glutationa peroxidase (GSHPX), peroxirredoxinas $(P R X)$ e tiorredoxinas (Trx); compostos de baixo peso molecular: ácido úrico (AU); ácido lipóico (AL); coenzima $Q(\mathrm{CoQ})$ e glutationa (GSH); tiol proteínas, como albumina, peroxirredoxinas e tiorredoxinas, e proteínas armazenadoras/ transportadoras de íons de metais de transição. As defesas antioxidantes exógenas referem-se aos antioxidantes obtidos por meio da alimentação, sendo os mais estudados o ácido ascórbico (Asc), $\alpha$-tocoferol $(\alpha-T H)$, carotenóides (CAR) $e$ polifenóis. Adaptado da ref. 23

tra os danos causados por estas espécies: as defesas antioxidantes. Para o funcionamento celular normal, deve haver uma compensação entre a formação de ROS/RNS e os níveis de defesas antioxidantes, que mantêm a célula em estado geral reduzido. Se as defesas antioxidantes tornam-se insuficientes frente à excessiva produção de ROS e RNS, ocorre o chamado estresse oxidativo. Estresse oxidativo agudo bem como estresse oxidativo crônico têm sido relacionados a um grande número de doenças degenerativas, como aterosclerose $^{12}$, diabetes ${ }^{12}$, injúria isquêmica ${ }^{13}$, doenças inflamatórias (artrite reumatóide ${ }^{14}$, colite ulcerativa ${ }^{15}$ e pancreatite ${ }^{16}$ ), câncer $^{17}$, doenças neurológicas (doença de Parkinson, esclerose lateral amiotrófica, síndrome de Down, doença de Alzheimer) ${ }^{18}$, hipertensão ${ }^{19}$, doenças oculares (degeneração macular relacionada ao envelhecimento e catarata) ${ }^{20}$, doenças pulmonares (asma e doença pulmonar obstrutiva crônica $)^{21}$. Os efeitos crônicos de ROS/RNS são considerados agentes importantes no processo de envelhecimento ${ }^{22}$.

Considerando-se que a produção de ROS/RNS e as defesas antioxidantes estejam em ajuste contínuo, pode-se supor que em algumas situações o balanço pode tender facilmente em favor das espécies reativas. $\mathrm{O}$ estresse oxidativo poderia ocorrer em várias situações patológicas ou ambientais que aumentem a produção de ROS/RNS e em conseqüência do consumo inadequado de antioxidantes derivados da dieta $^{23}$.

Halliwell e Gutteridge ${ }^{2}$ definiram antioxidante como alguma substância presente em concentrações baixas, comparadas às concentrações do substrato oxidante, que previne significativamente ou atrasa a oxidação de substratos susceptíveis. Os principais mecanismos de ação de compostos antioxidantes incluem captadores de radicais e supressores de estados excitados; sistemas catalíticos 
que neutralizam ou eliminam ROS/RNS e a ligação de íons metálicos a proteínas, o que os torna indisponíveis para a produção de espécies oxidantes.

Entre os principais antioxidantes encontrados no plasma humano estão proteínas/peptídeos com grupamento tiol (SH) (800$1000 \mu \mathrm{mol} / \mathrm{L})$, sendo a albumina a principal representante; ácido úrico (150-400 $\mu \mathrm{mol} / \mathrm{L})$; ácido ascórbico (30-150 $\mu \mathrm{mol} / \mathrm{L})$; tocoferol (20-50 $\mu \mathrm{mol} / \mathrm{L})$ e carotenóides $(0,08-3 \mu \mathrm{mol} / \mathrm{L})^{24}$.

\section{ANTIOXIDANTES DIETÉTICOS}

\section{Vitamina E}

Vitamina E (Figura 4) é um termo genérico que se refere a tocóis e tocotrienóis ( $\alpha, \beta, \delta, \gamma$ tocoferol e $\alpha, \beta, \delta, \gamma$ tocotrienol). Todos estes compostos consistem de um núcleo cromanol com uma cadeia alifática lateral. Há 60 anos estuda-se as propriedades da vitamina $\mathrm{E}$ contra doenças cardiovasculares, o que se atribui à sua capacidade antioxidante. $\mathrm{O}$ potencial antioxidante dos tocoferóis em meio biológico é diferente, sendo $\alpha>>\gamma>\delta>\beta^{25}$.
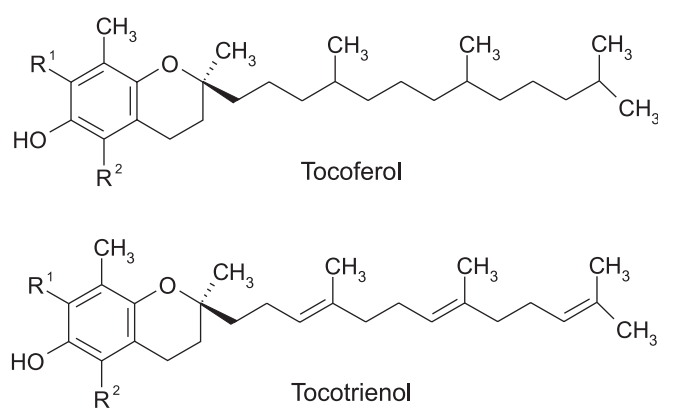

\begin{tabular}{cll} 
Tocoferol / Tocotrienol & $\mathrm{R}^{1}$ & $\mathrm{R}^{2}$ \\
\hline$\alpha-$ & $\mathrm{CH}_{3}$ & $\mathrm{CH}_{3}$ \\
$\beta-$ & $\mathrm{H}$ & $\mathrm{CH}_{3}$ \\
$\gamma-$ & $\mathrm{CH}_{3}$ & $\mathrm{H}$ \\
$\delta-$ & $\mathrm{H}$ & $\mathrm{H}$
\end{tabular}

Figura 4. Estrutura química do tocoferol e tocotrienol

Estudos in vitro demonstraram a capacidade superior do $\alpha$ tocoferol de prevenir a peroxidação lipídica de lipoproteínas de baixa densidade (LDL), principais responsáveis pelo transporte de ácidos graxos e colesterol do fígado para os tecidos periféricos ${ }^{26}$.

Radicais alquilperoxila (ROO*) são formados durante a peroxidação lipídica, iniciada por abstração de um átomo de hidrogênio dos PUFAs. Embora a peroxidação lipídica em níveis baixos pareça exercer papel fisiológico ${ }^{2}$, a peroxidação de PUFAs de membranas celulares pode afetar características importantes destas, como fluidez, permeabilidade, potencial elétrico e transporte controlado de metabólitos ${ }^{27}$.

A oxidação de lipídios por ROS/RNS pode ser dividida em três etapas, iniciação, progressão e terminação (Figura 5). Na progressão da lipoperoxidação podem ser formados hidrocarbonetos, álcoois, ésteres, peróxidos, epóxidos e aldeídos. Entre estes produtos, alguns exercem efeitos deletérios adicionais, como malondialdeído e 4-hidroxinonenal, que inativam fosfolipídios, proteínas e DNA, promovendo ligações cruzadas entre estas moléculas ${ }^{28}$.

Um mecanismo bem estabelecido de ação do $\alpha$-tocoferol é sua reação com o radical alquilperoxila. $\mathrm{O} \alpha$-tocoferol interrompe a reação em cadeia da peroxidação lipídica (Figura 5) seqüestrando os radicais alquilperoxila por meio da seguinte reação ${ }^{29}$ :

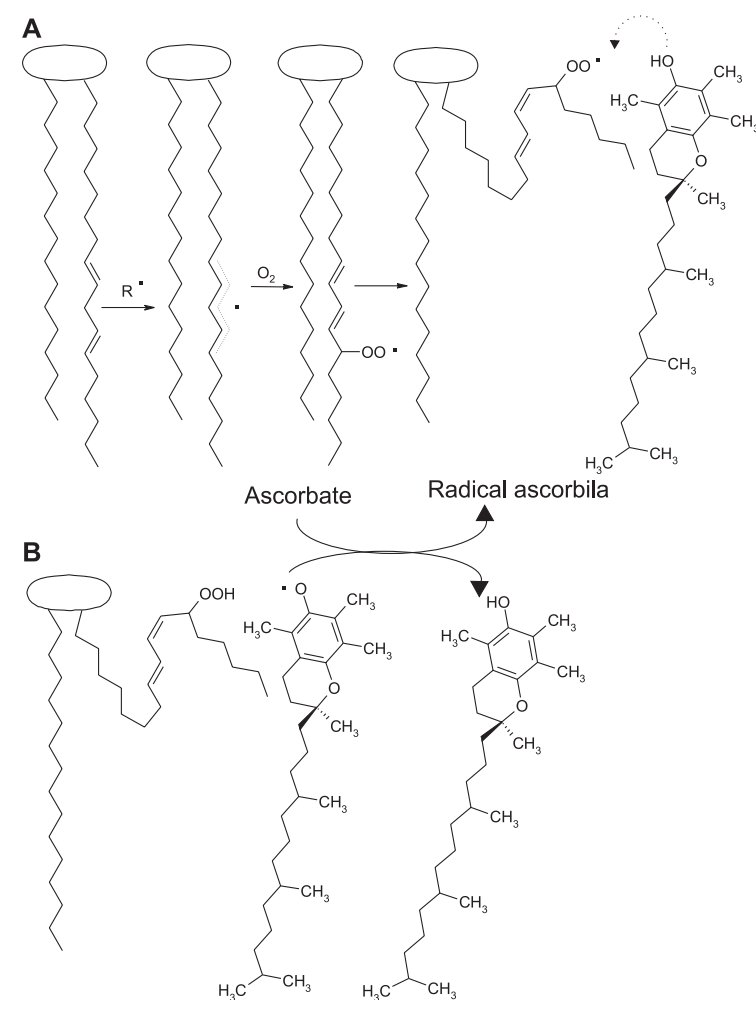

Figura 5. Etapas da lipoperoxidação e ação antioxidante do $\alpha$-tocoferol. (A) Iniciação: o grupo metileno de ácidos graxos poliinsaturados é atacado por radicais livres, havendo o rearranjo das duplas ligações na forma de dieno conjugado. Simultaneamente há formação de um radical alquila $\left(R^{*}\right)$ no carbono central. $\mathrm{O}$ radical alquila reage com $\mathrm{O}_{2}$ formando alquilperoxila (ROO*). Propagação: ROO* ataca outras moléculas de lipídios (não mostrado). Terminação: as reações em cadeia são interrompidas por interação entre os próprios radicais (não mostrado), ou (B) entre radicais e $\alpha$-tocoferol, originando produtos não-radicalares e o radical tocoferila. $O$ radical $\alpha$-tocoferila é reduzido por ação do ácido ascórbico

$\alpha-\mathrm{TH}+\mathrm{ROO}^{*} \rightarrow \alpha-\mathrm{T}^{*}+\mathrm{ROOH}$

Na ausência de vitamina E, a lipoperoxidação é propagada:

$\mathrm{ROO}^{*}+\mathrm{RH} \rightarrow \mathrm{ROOH}+\mathrm{R}^{*}$

$\mathrm{R}^{\cdot}+\mathrm{O}_{2} \rightarrow \mathrm{ROO}^{*}$

O elétron desemparelhado do radical $\alpha$-tocoferolila $\left(\alpha \mathrm{T}^{*}\right)$ resultante é delocalizado e, desta forma, é muito menos eficiente no ataque a cadeias laterais de ácidos graxos que o radical alquilperoxila (ROO*).

$\mathrm{O}$ efeito fisiológico do $\alpha$-TH é diminuir a velocidade das reações em cadeia verificadas na peroxidação de lipídios ${ }^{30}$.

Alguns mecanismos podem converter $\alpha-\mathrm{T}^{*}$ em $\alpha-\mathrm{TH}$, sendo a reação com ácido ascórbico na superfície das membranas e lipoproteínas a mais estudada ${ }^{28,30}$ (Figura 5). O $\alpha$-tocoferol foi relatado como importante no retardo do desenvolvimento de aterosclerose $^{31}$ e a deficiência desta vitamina, observada em pacientes com deficiência na absorção intestinal de gordura, está relacionada à neurodegeneração $0^{32}$.

Tendo em vista os benefícios antioxidantes do $\alpha$-tocoferol verificados in vitro e o fato de que a quantidade de $\alpha$-tocoferol presente em LDL (5-9 moléculas/partícula de LDL) é rapidamente alterada em resposta ao consumo dietético ${ }^{33}$, estudos em humanos têm sido realizados para verificar a eficácia da suplementação oral 
deste nutriente no retardo e na prevenção de doenças que envolvam lipoperoxidação.

Alguns estudos apresentaram resultados favoráveis no que diz respeito à redução da susceptibilidade da LDL à oxidação ${ }^{34,35}$; outros sugerem que $\alpha$-tocoferol pode apresentar atividade pró-oxidante em algumas situações, por ex. em pessoas fumantes ou que consumam quantidade elevada de PUFAs ${ }^{36}$. A partir destes resultados contraditórios, estudos in vitro têm demonstrado que em doses elevadas o $\alpha$-tocoferol pode agir como pró-oxidante, caso não haja concentrações equivalentes de outros antioxidantes para regenerar o radical $\alpha$-tocoferila a $\alpha$-tocoferol ${ }^{25}$.

Há evidências crescentes de que os mecanismos protetores do $\alpha$ tocoferol não são apenas correlacionados com a prevenção da oxidação da LDL, mas também com funções não-antioxidantes. A vitamina $E$ atua em nível celular, inibindo a proliferação de células musculares lisas das artérias, a agregação plaquetária, a adesão de monócitos à parede do endotélio, a captação de LDL oxidada e a produção de citocinas. Estes mecanismos parecem estar relacionados com efeitos específicos do $\alpha$ tocoferol na transdução de sinais e expressão gênica ${ }^{25,37}$.

\section{Ácido ascórbico (vitamina C)}

A vitamina $\mathrm{C}$ é um nutriente hidrossolúvel envolvido em múltiplas funções biológicas. É cofator de várias enzimas envolvidas na hidroxilação pós-tradução do colágeno, na biossíntese de carnitina, na conversão do neurotransmissor dopamina a norepinefrina, na amidação peptídica e no metabolismo da tirosina. Adicionalmente, é importante na absorção do ferro dietético, devido a sua capacidade de reduzir a forma férrica $\left(\mathrm{Fe}^{3+}\right)$ a ferrosa $\left(\mathrm{Fe}^{2+}\right)$, propiciando absorção do ferro não-heme no trato gastrointestinal ${ }^{28,29,38}$.

O gene responsável pela enzima-flavo L-gulono-1,4-lactona oxidase, envolvido na síntese de ácido ascórbico, não é transcrito em humanos e alguns outros mamíferos, embora esteja presente no genoma. Sabe-se que a via endógena de síntese é fonte de ROS; assim, do ponto de vista evolutivo, a perda da capacidade de sintetizar ácido ascórbico é considerada benéfica e metabolicamente econômica, visto que a dieta é capaz de suprir a deficiência endógena ${ }^{1,39}$. A privação prolongada de vitamina $\mathrm{C}$ dietética acarreta defeito na modificação pós-tradução do colágeno, levando ao escorbuto e, ocasionalmente, à morte. $\mathrm{O}$ escorbuto pode ser prevenido pelo consumo diário de $10 \mathrm{mg}$ de vitamina $\mathrm{C}$. Acredita-se, todavia, que doses mais elevadas são necessárias para manutenção de uma saúde desejável ${ }^{40}$.

Além da importante função anti-escorbútica, a vitamina $\mathrm{C}$ é um potente agente redutor $\left(\mathrm{E}^{\circ}=-170 \mathrm{mV}\right)$, capaz de reduzir a maioria das ROS/RNS fisiologicamente relevantes ${ }^{2}$. Em meio fisiológico encontra-se predominantemente na forma de monoânion ascorbato ${ }^{41}$.

O ácido ascórbico reduz ROS/RNS em leucócitos ativados, pulmão e mucosa gástrica. No trato respiratório pode reagir rapidamente com poluentes do ar, como $\mathrm{O}_{3}$, fumaça de cigarro e $\mathrm{NO}_{2}$. Além de eliminar diretamente ROS/RNS, regenera o $\alpha$-tocoferol e, portanto, participa do mecanismo protetor contra lipoperoxidação. Uma vez que a vitamina $\mathrm{C}$ é depletada, outros compostos antioxidantes (ácido úrico e proteínas contendo tiol) podem reduzir o radical $\alpha$-tocoferila, mas de forma menos eficiente ${ }^{42}$.

Os produtos da oxidação do $\mathrm{AscH}^{-}$por um elétron e por dois elétrons são, respectivamente, radical ascorbila e ácido desidroascórbico (Figura 6). O radical ascorbila, entretanto, é relativamente não reativo, quando comparado a outros radicais livres. Esta propriedade torna o ácido ascórbico um eficiente antioxidante, capaz de eliminar espécies altamente reativas e formar um radical de reatividade baixa ${ }^{41}$.

$\mathrm{O}$ radical ascorbila pode ser convertido novamente em ácido ascórbico por redutases dependentes de NADH ou por dismutação de duas moléculas do radical em uma de $\mathrm{AscH}^{-}$e uma de ácido

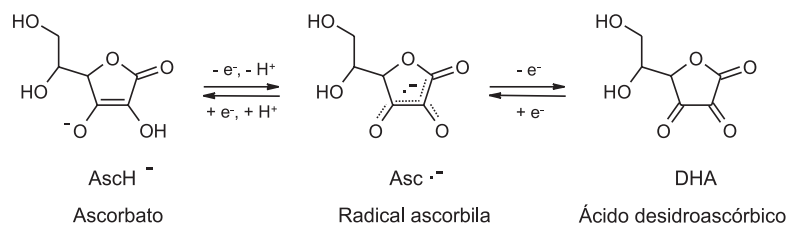

Figura 6. A oxidação do ácido ascórbico por um elétron (e-) forma o radical ascorbila que, ao ser oxidado novamente, gera ácido desidroascórbico. Os elétrons são recebidos por compostos oxidantes

desidroascórbico. Este último é pouco estável em pH fisiológico, geralmente é reduzido a $\mathrm{AscH}^{-}$, ou hidrolisado irreversivelmente ${ }^{43}$. $\mathrm{O}$ radical ascorbila não é prontamente reduzido, pode permanecer até 2 h no plasma ex vivo. Em situação de estresse oxidativo, os níveis de radical ascorbila são elevados; assim, este radical tem sido usado como indicador de estresse oxidativo em fluidos corpóreos ${ }^{44}$.

Apesar da grande eficiência antioxidante, a vitamina $\mathrm{C}$ também age paradoxalmente como pró-oxidante in vitro. Soluções de vitamina $\mathrm{C}$ e ferro são usadas há décadas para induzir modificações oxidativas em lipídios, proteínas e DNA². A reação de Fenton, redução de peróxido de hidrogênio por $\mathrm{Cu}^{1+}$ ou $\mathrm{Fe}^{2+}$ a radical hidroxila, é favorecida na presença de vitamina $\mathrm{C}$, capaz de reduzir os metais de transição, tornando-os aptos para esta reação. In vivo os metais encontram-se complexados em proteínas, portanto, indisponíveis ${ }^{45}$. Já em situações patológicas em que a quantidade de ferro e/ou cobre livre está elevada, por ex. talassemias, hemocromatose e injúria tecidual, a atividade pró-oxidante pode ser relevante ${ }^{46}$.

Muitos estudos de intervenção em humanos relacionam suplementação com vitamina $\mathrm{C}$ e lesões oxidativas em DNA, incluindo lesão nas bases nitrogenadas e quebra de fita do DNA. Os resultados apresentados são contraditórios. Já se verificou decréscimo ${ }^{47} \mathrm{e}$ aumento ${ }^{48}$ das lesões e em alguns casos os efeitos foram nulos ${ }^{49}$.

Atualmente a vitamina $C$ também é muito estudada no tratamento do câncer. Acredita-se que estimule o sistema imune, iniba a formação de nitrosaminas e bloqueie a ativação metabólica de carcinógenos. Contudo, células tumorais parecem necessitar de ácido ascórbico e competem com células saudáveis por este nutriente, presumivelmente para se defenderem da ameaça oxidativa, uma vez que tumores tratados com vitamina $\mathrm{C}$ se tornam mais resistentes à injúria oxidativa ${ }^{38,50}$.

Apesar dos dados contraditórios, a importância da vitamina C como antioxidante é bem estabelecida, considerando-se as doses recomendadas, geralmente alcançadas por meio da alimentação. Além da captação de radicais livres, estudos em cultura de células demonstram que a vitamina $\mathrm{C}$ pode alterar a expressão de genes envolvidos na resposta inflamatória ${ }^{51}$, apoptose ${ }^{52}$ e diferenciação celular $^{53}$. $\mathrm{O}$ mecanismo pelo qual a vitamina $\mathrm{C}$ altera a expressão de genes é desconhecido, mas supõe-se que atue indiretamente na expressão gênica, alterando a expressão de genes responsivos a espécies oxidantes ou diretamente, modulando a ligação de alguns fatores de transcrição ao núcleo ${ }^{54}$.

\section{Carotenóides}

Carotenóides são isoprenóides (Figura 7), geralmente constituídos por 8 unidades de isoprenos, formando uma longa cadeia de polieno que pode conter de 2 a 15 duplas ligações conjugadas, o que permite muitas configurações cis e trans. São amplamente distribuídos na natureza, sintetizados exclusivamente em plantas e responsáveis pela coloração de frutas e hortaliças ${ }^{55}$.

Desde a década de 50 a atividade pró-vitamina A de alguns carotenóides é estudada. Já no início dos anos 90 surgiu o interesse no papel antioxidante destes compostos, que vem sendo relacionado 


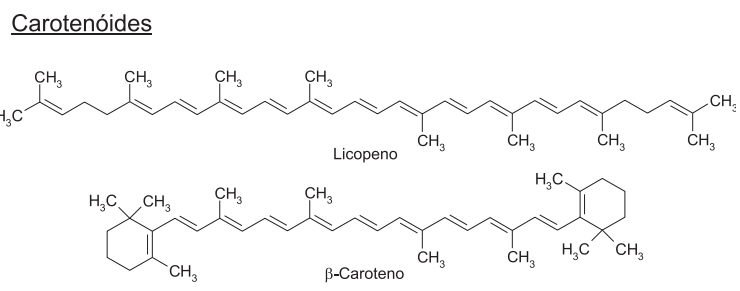

Xantofilas (Oxicarotenóides)

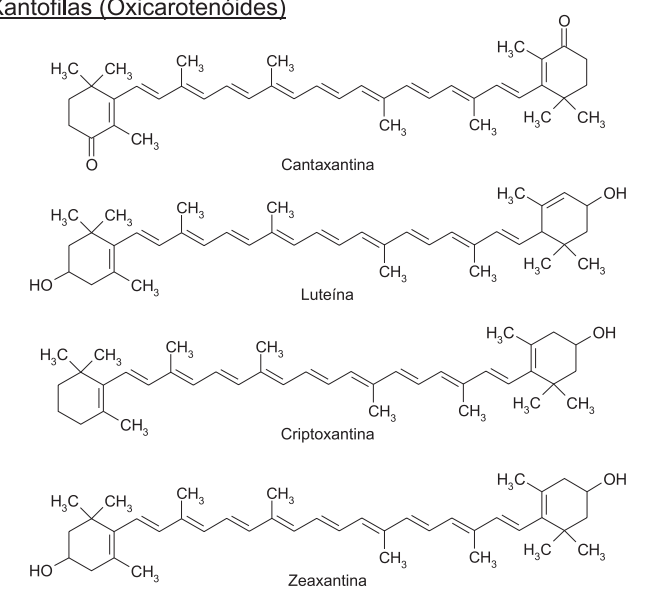

Figura 7. Estrutura química dos principais carotenóides dietéticos

à proteção contra doenças crônico-degenerativas não transmissíveis.

Dos cerca de 600 carotenóides identificados, somente 20 são encontrado em tecidos humanos e são provenientes da dieta. Entre estes, os principais incluem os hidrocarbonetos licopeno e $\beta$-caroteno, e as xantofilas, astaxantina, cantaxantina, luteína e zeaxantina. São compostos lipofílicos encontrados em tecido adiposo, lipoproteínas e membranas celulares. A cadeia de polieno e outras características estruturais influenciam suas características químicas, a localização e orientação dos carotenóides no interior da bicamada lipídica em ambientes bioló$\operatorname{gicos}^{56}$.

As concentrações plasmáticas de carotenóides são bons indicadores do consumo de frutas e hortaliças; evidências epidemiológicas associam altos níveis plasmáticos de $\beta$-caroteno e outros carotenóides com risco diminuído de câncer e doenças cardiovasculares. As propriedades antioxidantes dos carotenóides fundamentam-se na estrutura destes compostos, principalmente no sistema de duplas ligações conjugadas, tornando possível a captação de radicais livres, principalmente o radical alquilperoxila $\left(\mathrm{ROO}^{*}\right)^{57,58}$.

Além da captação de radicais livres, os carotenóides captam energia do oxigênio singlete, que volta ao estado fundamental $\left(\mathrm{O}_{2}\right)$. O carotenóide excitado resultante libera energia baixa e, portanto, inofensiva ao meio celular ${ }^{59}$. Este mecanismo protege os portadores de porfirias cutâneas contra os efeitos deletérios do oxigênio singlete formado na pele a partir da exposição à luz solar. Tais efeitos protetores são indicados pela redução da concentração de $\beta$-caroteno na pele dos indivíduos afetados ${ }^{60,61}$.

Estrutura (tamanho, natureza, posição e números de grupos substituintes), forma física (agregados ou monômeros, configuração cis ou trans, etc), localização ou sítio de ação da molécula carotenóide dentro da célula, potencial de interação com outros carotenóides ou antioxidantes (especialmente vitaminas $\mathrm{C}$ e E), concentração do carotenóide e pressão parcial de oxigênio são todos fatores que influenciam a atividade dos carotenóides em sistemas biológicos ${ }^{57}$.

Entre as reações in vitro bem estabelecidas dos antioxidantes carotenóides (CAR), encontram-se as reações com radical alquilperoxila (ROO*) que se dão ao menos por três vias ${ }^{56}$ :
$\mathrm{CAR}+\mathrm{ROO}^{*} \rightarrow \mathrm{CAR}^{*+}+\mathrm{ROO}^{-}$(transferência de elétrons)

$\mathrm{CAR}+\mathrm{ROO}^{*} \rightarrow \mathrm{CAR}^{*}+\mathrm{ROOH}$ (abstração de hidrogênio)

$\mathrm{CAR}+\mathrm{ROO}^{*} \rightarrow \mathrm{ROOCAR}^{\bullet}($ adição)

In vivo, o conteúdo e a composição tecidual de carotenóides são heterogêneos. Em ambientes apolares, como tecido adiposo e interior de membranas plasmáticas, a separação de carga é termodinamicamente desfavorável, e a reação (10) (transferência de elétrons) é improvável para licopeno e $\beta$-caroteno (hidrocarbonetos). Contudo, dióis carotenóides, como zeaxantina, possuem grupamentos polares, podendo interceptar radicais no meio aquoso e na superfície de membranas. Uma vez que o cátion radical carotenóide $\left(\mathrm{CAR}^{++}\right)$é formado, pode oxidar diferentes compostos no ambiente aquoso ${ }^{56,60}$.

Woodall et al. ${ }^{61}$ demonstraram que $\beta$-criptoxantina e zeaxantina foram mais efetivas como antioxidantes contra radical alquilperoxila (ROO') em membranas lipossomais que $\beta$-caroteno e licopeno. Zeaxantina e $\beta$-caroteno possuem o mesmo comprimento de cadeia conjugada $\mathrm{C}=\mathrm{C}$ e o mesmo comportamento em solução aquosa; portanto, as diferenças observadas devem-se provavelmente à localização e orientação destes no interior da bicamada lipídica.

Geralmente os radicais carotenóides, assim como os radicais tocoferila e ascorbila, são estabilizados por ressonância e, portanto, pouco reativos. Eles podem decair por meio de reações com outros radicais, formando produtos estáveis. Contudo, os diferentes mecanismos pelos quais os carotenóides podem captar radicais levam a uma variedade de radicais carotenóides que, por sua vez, levam a múltiplos produtos finais. O potencial protetor ou deletério destes produtos finais depende da natureza do radical, de seu meio ambiente (aquoso ou lipídico) e de características estruturais, como terminal cíclico ou acíclico, grupos finais polares ou apolares, propriedades redox, etc ${ }^{56}$.

Experimentos recentes mostraram que em concentrações elevadas a capacidade antioxidante de carotenóides foi diminuída e licopeno, luteína e $\beta$-caroteno apresentaram efeitos pró-oxidantes. Em altas concentrações eles podem alterar as propriedades de membranas biológicas, influenciando a permeabilidade a toxinas, ao oxigênio ou metabólitos ${ }^{56}$.

Em concentrações elevadas de $\mathrm{O}_{2}$ verifica-se auto-oxidação dos carotenóides e redução da atividade antioxidante o que, in vitro, parece perpetuar a peroxidação lipídica. No pulmão, a pressão de $\mathrm{O}_{2}$ é de aproximadamente $150 \mathrm{~mm} \mathrm{Hg}$ e pode propiciar a perda da eficácia antioxidante de carotenóides. Já nos tecidos periféricos, a eficácia dos carotenóides pode ser maior porque a pressão de oxigênio é de 5$15 \mathrm{~mm} \mathrm{Hg}$. Ao contrário, o $\alpha$-tocoferol é muito mais efetivo em altas concentrações de $\mathrm{O}_{2}$, exemplificando o quanto os antioxidantes podem atuar de forma cooperativa em diferentes tecidos ${ }^{57,62}$.

Embora estudos com animais demonstrem que a suplementação com $\beta$-caroteno protege contra o câncer em algumas situações, estudos populacionais mostraram efeitos nulos ou negativos. $\mathrm{O}$ estudo populacional CARET ("The Beta Carotene and Retinol Efficacy Trial") realizado com 18000 fumantes norte-americanos em que se administrou $\beta$-caroteno e vitamina A na forma de suplementos, previsto para durar 5 anos, foi encerrado 21 meses antes devido a uma tendência de aumento no desenvolvimento de câncer de pulmão e da mortalidade ${ }^{63}$. O estudo anterior, ATBC "Alpha-Tocopherol BetaCarotene", também realizado em fumantes, apresentou igual tendência nos grupos suplementados com $\beta$-caroteno e $\beta$-caroteno e $\alpha$ tocoferol, o que não foi observado na suplementação apenas com $\alpha$ tocoferol $^{64}$. Não há consenso entre os pesquisadores em relação à atividade pró-oxidante dos carotenóides, mas os estudos já realizados permitem concluir que em sistemas biológicos existem muitos fatores que podem reduzir a eficácia antioxidante destes compos$\operatorname{tos}^{57}$. 
Assim, estudos adicionais são necessários para confirmar se os benefícios dos carotenóides relacionam-se às propriedades antioxidantes ou a outras atividades biológicas. Criptoxantina, zeaxantina e $\beta$-caroteno são carotenóides que apresentam atividade pró-vitamina $\mathrm{A}$, ou seja, são convertidos endogenamente a retinóides. Os carotenóides estimulam comunicações "gap junctions" entre células, sendo a comunicação celular essencial para a coordenação de funções bioquímicas em organismos complexos $^{56}$. A participação dos carotenóides na comunicação celular, regulação da transcrição de alguns genes e conversão em retinóides pode ser tão ou mais importante que a atividade antioxidante nos efeitos fisiológicos atribuídos a estes compostos ${ }^{58,65}$.

\section{Polifenóis}

Polifenóis são os antioxidantes mais abundantes da dieta. O consumo diário pode atingir $1 \mathrm{~g}$, o que é muito maior que o consumo de todos os outros fitoquímicos classificados como antioxidantes ${ }^{66}$. Apesar da distribuição abundante em plantas, os efeitos destes compostos na saúde humana tornaram-se foco de atenção apenas na década de 90.

As plantas sintetizam centenas de compostos fenólicos e polifenólicos (Figura 8), que possuem variadas estruturas e funções. Entre estes compostos, os mais estudados como antioxidantes são os flavonóides que têm em comum a estrutura $\mathrm{C}_{6}-\mathrm{C}_{3}-\mathrm{C}_{6}$, consistindo de dois anéis aromáticos ligados por um heterocíclico oxigenado. Dentre os aproximados 4000 flavonóides já descritos, as maiores classes são flavonóis, catequinas ou flavonas, antocianidinas e isoflavonas. Nestas classes há grandes variações estruturais, dependendo do nível de hidrogenação, hidroxilação, metilação e sulfonação das moléculas. Além disso, flavonóides formam complexos com açúcar, lipídios, aminas e ácidos carboxílicos ${ }^{67,68}$.

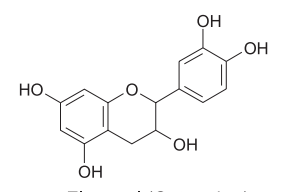

Flavanol (Catequina)

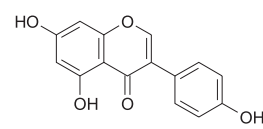

Isoflavona (Genisteina)
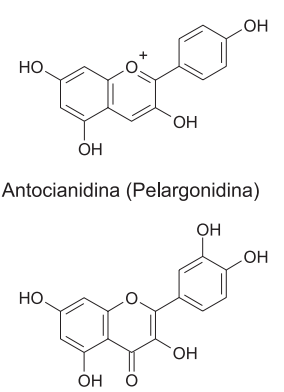

Flavonol (Quercetina)
Antocianidina (Pelargonidina)

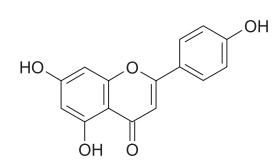

Flavona (Apigenina)

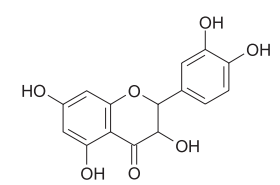

Flavanona (Taxifolina)
Figura 8. Estrutura das principais classes de flavonóides

Numerosos estudos in vitro indicam que polifenóis encontrados em plantas podem efetivamente participar de processos que possam ter implicações anti-carcinogênicas e anti-aterogênicas. Entre estes processos, o mais evidente é a capacidade antioxidante destes compostos atribuída ao poder redutor do grupo hidroxila aromático, que reduz radicais livres reativos e produz o radical fenoxila estabilizado por ressonância. A capacidade antioxidante dos polifenóis é influenciada pelo número e posição dos grupos $\mathrm{OH}$, assim como pelas posições de glicosilação ${ }^{68,69}$. Ao contrário do ácido ascórbico e $\alpha$ - tocoferol, que agem em meio aquoso e na camada fosfolipídica, respectivamente, os flavonóides podem se localizar nas duas fases ${ }^{68}$.

Alguns flavonóides, como quercetina, apresentam maiores velocidades de reação com radicais livres in vitro que o $\alpha$-tocoferol. Postula-se que isto seja devido à conjugação mais estendida de suas estruturas, que leva a radicais mais estabilizados. A presença de 2 ou mais grupos $\mathrm{OH}$ reativos e menor impedimento estérico no sítio de abstração também devem influir ${ }^{68}$.

Os polifenóis são capazes de captar radicais alcoxila (RO*), alquilperoxila ( $\left.\mathrm{ROO}^{*}\right)$, superóxido $\left(\mathrm{O}_{2}^{*}\right)$, radical hidroxila $\left(\mathrm{HO}^{*}\right)$, óxido nítrico $\left(\mathrm{NO}^{\circ}\right)$, além do oxidante peroxinitrito ( $\mathrm{ONOO}^{-} /$ $\mathrm{ONOOH}$ ). A eficácia antioxidante de polifenóis in vivo ainda precisa ser melhor avaliada, pois pouco se conhece sobre suas biodisponibilidades ${ }^{67}$.

Alguns efeitos tóxicos do alcoolismo crônico têm sido associados à produção de ROS/RNS. Todavia, dados epidemiológicos demonstraram que indivíduos que consomem bebidas alcoólicas moderadamente apresentam níveis elevados de HDL (lipoproteína de alta densidade), o que implica em menor risco de desenvolvimento de doenças cardiovasculares $^{70}$. Além disso, o consumo de vinho tinto tem sido associado à proteção contra doenças relacionadas à idade, o que é conhecido como "Paradoxo Francês". Os benefícios observados particularmente em relação ao vinho tinto estão associados a seu elevado conteúdo de flavonóides, principalmente resveratrol e quercitinas ${ }^{68}$.

As catequinas presentes em grandes quantidades no chá verde e cacau estão entre os flavonóides polifenólicos mais potentes como antioxidantes, de acordo com estudos in vitro ${ }^{54,71}$. O elevado consumo de azeite de oliva na dieta mediterrânea relaciona-se com menor incidência de doenças cardiovasculares e alguns tipos de câncer, sendo que as características antioxidantes dos flavonóides hidroxitirosol e oleuropeína foram relacionadas aos benefícios relatados e à elevada estabilidade deste óleo poliinsaturado ${ }^{72}$.

Embora os estudos in vitro indiquem a eficácia de polifenóis como antioxidantes, e a possível relação entre estas substâncias e a redução de oxidações envolvidas em doenças cardiovasculares, resultados favoráveis são obtidos em concentrações que variam de $<0,1$ a $>100 \mu \mathrm{mol} / \mathrm{L}$. Os níveis fisiológicos geralmente encontram-se em torno de $1 \mu \mathrm{mol} / \mathrm{L}$; desta forma, nem todos os polifenóis consumidos apresentarão atividade antioxidante ${ }^{73,74}$.

Estudos em humanos voltados para a relação entre consumo aumentado de polifenóis e proteção à saúde têm demonstrado, em alguns casos, reduções em indicadores de danos oxidativos a biomoléculas, como excreção urinária de 8-hidroxi-desoxiguanosina, quebra de fitas de DNA e LDL oxidada ${ }^{75}$. Ressalta-se que na maioria dessas intervenções utilizou-se a administração de fontes dietéticas de polifenóis específicos, diferentemente dos estudos populacionais com outros antioxidantes.

Além dos efeitos antioxidantes, acredita-se que os polifenóis podem exercer efeitos diretos no trato gastrointestinal. Entre esses efeitos inclui-se a ligação a inibidores de telomerase, regulação de vias de transdução de sinal, inibição de ciclooxigenase e lipooxigenase, redução das atividades de xantina oxidase, de metaloproteinase de matriz e da enzima conversora de angiotensina, a competição com glicose para transporte transmembrana e a alteração da função de plaquetas $^{75}$.

\section{RECOMENDAÇÕES DIETÉTICAS E BIODISPONIBILIDADE}

As doses dietéticas de vitamina $\mathrm{C}$ e $\alpha$-tocoferol recomendadas pela "Recommended dietary allowance- RDAs" (1989) foram elevadas em 2000. Os dados referentes às necessidades destes nutrientes, bem como a recomendação média para a população e dose máxima tolerável estão compilados na publicação "Dietary Reference Intakes for Vitamin C, Vitamin E, Selenium, and Carotenoids" ${ }^{41}$. Apesar dos avanços na área, os dados disponíveis são limitados e insuficientes pois não consideram a variação das necessidades dietéticas entre grupos de indivíduos em diferentes estados fisiológicos. Além disso, essas recomendações partiram de pesquisas populacionais realiza- 
das nos Estados Unidos e podem não representar fidedignamente as necessidades dos brasileiros.

Em resposta aos benefícios comprovados, a recomendação norte-americana diária para consumo de vitamina $\mathrm{C}$ foi elevada para 75 mg para mulheres e $90 \mathrm{mg}$ para homens. Isto não corresponde nem à décima fração dos $2 \mathrm{~g}$ propostos por Pauling ${ }^{40}$ como ideais para manutenção da saúde e é bem inferior à quantidade consumida diariamente por nossos ancestrais paleolíticos. A biodisponibilidade de vitamina $\mathrm{C}$ consumida por meio de frutas e hortaliças é de aproximadamente $100 \%$, mas se observa saturação nos tecidos humanos com consumo acima de $200 \mathrm{mg} / \mathrm{dia}$, e relativamente menos ácido ascórbico é absorvido aumentando-se o consumo ${ }^{76}$.

A vitamina $\mathrm{C}$ é bem absorvida no trato gastrointestinal. Os níveis plasmáticos podem ser aumentados em resposta à dieta rica em frutas e hortaliças por tempo prolongado e em casos de suplementação $0^{77,78}$. Alguns estudos têm demonstrado que o aumento plasmático de vitamina $\mathrm{C}$ reflete-se no meio intracelular, embora de forma não dependente da dose, provavelmente devido à saturação ${ }^{79}$.

Todas as formas de vitamina E são absorvidas nos enterócitos e liberadas na circulação dentro de quilomícrons. Ao chegar ao fígado, a proteína de transferência de $\alpha$-tocoferol ( $\alpha$-TTP) o incorpora em lipoproteínas de densidade muito baixa (VLDL). As outras formas são muito menos retidas e, geralmente, excretadas na urina ou com a bile. Afinidades relativas de análogos do tocoferol pela $\alpha$ TTP são calculadas a partir da competição com a forma $\alpha$, sendo $\alpha$ tocoferol 100\%, $\beta$-tocoferol, 38\%, $\gamma$-tocoferol, $9 \%, \delta$-tocoferol, $2 \%{ }^{80}$.

Sabe-se que a absorção de carotenóides é influenciada pelo tipo de alimento em que se encontram. Carotenóides usados como corantes em alimentos são melhor absorvidos. A absorção a partir de hortaliças e frutas só é possível se o carotenóide for liberado das fibras alimentares, o que ocorre apenas com a mastigação eficiente ou o processamento industrial. A solubilidade destes compostos também é fator limitante. São absorvidos junto com micelas de lipídeos; portanto, é necessário o consumo concomitante de alguma fonte lipídica e isto também se aplica aos suplementos. Nos enterócitos são incorporados em quilomícrons e transportados ao longo da corrente sanguínea e no fígado passam para as $\mathrm{LDLs}^{81}$.

Inicialmente acreditava-se que a absorção de polifenóis era insignificante, por volta de $1-25 \%$, principalmente porque a maioria está ligada a glicosídeos que não são clivados por enzimas digestivas humanas. Contudo, estudos recentes demonstraram até $50 \%$ de absorção de alguns flavonóides ${ }^{67,73}$. Apesar de todos os benefícios provenientes da capacidade antioxidante dos polifenóis, ressalta-se seu papel como quelante de nutrientes, como ferro, cálcio, aminoácidos e proteínas no trato gastrointestinal. Por isso, foram denominados compostos anti-nutricionais durante décadas, e seu consumo elevado (suplementação) pode estar associado à redução da biodisponibilidade de outros nutrientes ${ }^{71}$.

A biodisponibilidade de carotenóides e polifenóis é variável e influenciada por fatores como transporte, biotransformação e excreção, que permanecem pouco compreendidos; assim, mais estudos serão necessários para o estabelecimento de recomendações dietéticas mais específicas ${ }^{1}$.

\section{CONTROVÉRSIAS}

Apesar de evidências epidemiológicas relacionarem o consumo de frutas e hortaliças com o decréscimo na incidência de doenças crônico-degenerativas não transmissíveis, a suplementação com vitamina $E$, ascorbato e $\beta$-caroteno não apresentou efeito semelhante na maioria dos ensaios de intervenção ${ }^{82}$. Pode-se elencar algumas explicações para esta dicotomia. O $\beta$-caroteno é apenas um dos 600 carotenóides identificados, pode não ser o mais ativo e pode, ainda, inibir a absorção de carotenóides mais quimiopreventivos. Os alimentos são fontes de vários nutrientes que devem atuar de forma cooperativa na prevenção de doenças; por isso, os estudos com frutas e hortaliças apresentam resultados mais significativos no que diz respeito à proteção da saúde que estudos com nutrientes isolados. Os níveis plasmáticos de antioxidantes dietéticos podem servir exclusivamente como marcadores úteis de uma alimentação saudável ${ }^{41}$. A ação preventiva de antioxidantes pode ocorrer precocemente na progressão da doença, mas ser ineficaz posteriormente. Assim, indivíduos de grupos identificados como de alto risco podem ser resistentes aos suplementos. As associações verificadas na epidemiologia observacional não são causais e podem ser confundidas por uma variedade de fatores não previstos e nem determinados ${ }^{76,83}$.

Além das controvérsias existentes entre as observações epidemiológicas e os ensaios de intervenção, questiona-se até que ponto as estratégias de aumento de defesas antioxidantes por meio de nutrientes seriam benéficas, considerando-se que o excesso consumido poderá, ao longo da evolução, remover a pressão que modela sistemas endógenos, levando a uma sub-regulação ou não expressão de genes envolvidos com a defesa antioxidante endógena. Um processo deste tipo pode ter ocorrido com a biossíntese de ácido ascórbico no período Paleolítico ${ }^{1}$.

As células humanas geralmente encontram-se em estado reduzido, mas algum grau de oxidação localizada é necessário para funções importantes, de forma que a sobrecarga de compostos redutores pode influir negativamente em suas funções normais ${ }^{83}$.

Um excesso de antioxidantes redutores pode acarretar inibição da proliferação celular, por prevenir o estado transitório de oxidação e diminuir a adaptação ao estresse oxidativo. Pode ainda reduzir metais de transição livres que se tornam potentes catalisadores de reações em cadeia iniciadas por radicais livres ${ }^{83}$.

Apesar dos efeitos controversos observados, sabe-se que muitos indivíduos se auto-medicam com suplementos vitamínicos e minerais. Estima-se que $50 \%$ dos pacientes com câncer consumam algum tipo de suplemento, o que pode acarretar efeitos adversos ${ }^{1}$. Tendo em vista que muitos suplementos são uma mistura de vitaminas e minerais, o prejuízo para a saúde pode ser ainda maior, visto que no trato gastrointestinal há competição entre algumas classes de nutrientes para absorção. Além disso, suplementos que contenham ferro e vitamina $\mathrm{C}$ em quantidades elevadas podem representar perigo para o balanço redox.

\section{PERSPECTIVAS}

\section{Estudos promissores}

Publicações recentes sugerem que os antioxidantes são eficazes na prevenção de doenças crônicas associadas ao estresse oxidativo quando administrados a grupos que apresentem concentrações plasmáticas inadequadas destes micronutrientes. O estudo SU.VI.MAX (The Supplémentation en Vitamines et Minéraux Antioxydants) que acompanhou milhares de franceses durante 7,5 anos recebendo doses diárias de ácido ascórbico, $\alpha$-tocoferol e $\beta$ caroteno concluiu que a redução da incidência de câncer e da mortalidade foi significativa entre as pessoas do sexo masculino. Estes apresentavam deficiência nos níveis plasmáticos dos antioxidantes administrados antes do estudo ${ }^{84}$. Esta intervenção seguiu os moldes do estudo de Linxian no que diz respeito às doses da suplementação, próximas às recomendações nutricionais preconizadas nos Estados Unidos. Os indivíduos de Linxian, China, que receberam doses baixas de suplementação de $\beta$-caroteno, vitamina E e selênio apresentaram significativa redução no desenvolvimento de câncer. Tam- 
bém apresentavam inadequação nos níveis plasmáticos dos antioxidantes administrados.

Não existem evidências de que o consumo de alimentos ricos em antioxidantes ao longo da vida acarrete efeitos prejudiciais. Ao contrário, há fortes evidências epidemiológicas de que estejam associados a um envelhecimento saudável e à longevidade funcional. Todos os estudos que apresentaram resultados controversos utilizaram antioxidantes na forma de suplementos ${ }^{1}$.

A dieta mediterrânea, rica em frutas, hortaliças, grãos e óleos monoinsaturados está associada à menor mortalidade por doenças crônico-degenerativas não transmissíveis. Dois estudos prospectivos que acompanharam durante 10 anos homens e mulheres com idade entre 70 e 90 anos que aderiram à dieta mediterrânea e estilo de vida saudável (ausência de tabagismo, prática de atividade física e consumo moderado de álcool) demonstraram que a mortalidade por doenças cardiovasculares, coronárianas e câncer foi $50 \%$ menor entre estes indivíduos. $\mathrm{O}$ fator que se correlacionou mais fortemente com a redução dos riscos de mortalidade foi a dieta mediterrânea ${ }^{85}$.

Em vista dos benefícios atribuídos ao consumo de frutas e hortaliças contra doenças, surgiram as recomendações dietéticas de consumo de 5 a 9 porções diárias destes alimentos, que o "World Cancer Research Fund and the American Institute for Cancer Research" associou a decréscimo de $14 \%$ no risco de desenvolvimento de câncer ${ }^{86}$. Nos dias de hoje, o foco sobre a dieta como fator chave na determinação da estabilidade genômica aumentou muito em relação ao que se imaginava anteriormente ${ }^{82}$. De fato, muitos micronutrientes são coenzimas de enzimas envolvidas em reparo e síntese de DNA e apoptose.

Em síntese, o conjunto de nutrientes presente nos alimentos parece propiciar proteção à saúde, e não um nutriente isolado ${ }^{79}$. De fato, os antioxidantes não atuam sozinhos, agem em sinergia, sendo

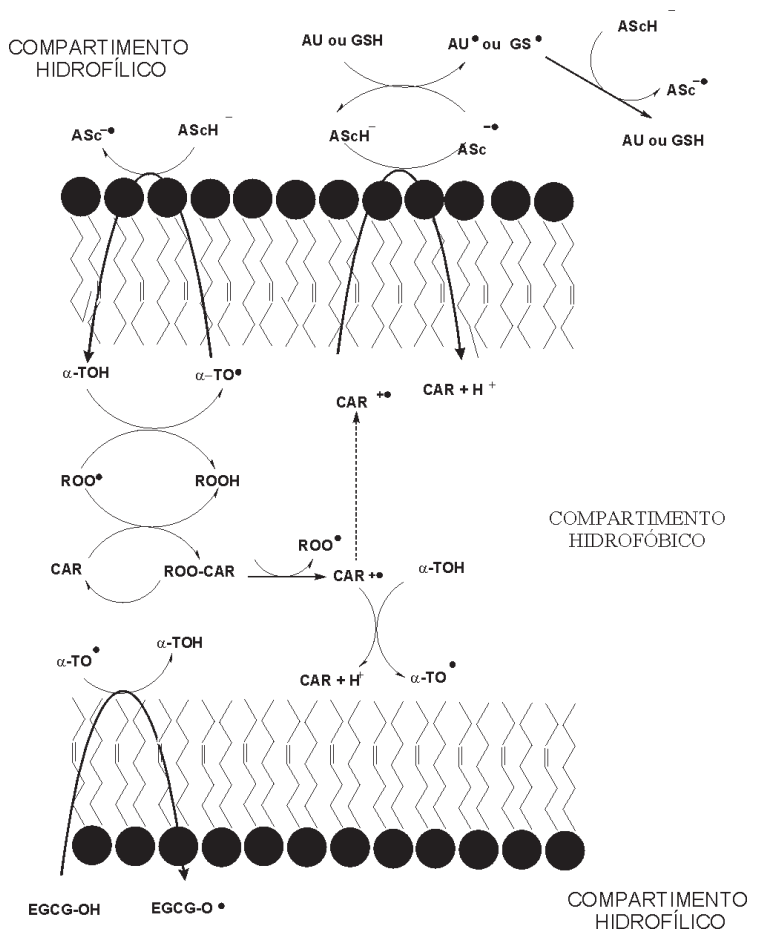

Figura 9. Interações cooperativas entre antioxidantes localizados em compartimentos hidrofílico e hidrofóbico. AscH - ácido ascórbico; ASC* radical ascorbila; $C A R$ - carotenóide; $C A R^{*+}$ - cátion radical carotenóide; $\alpha$ $\mathrm{TOH}$ - $\alpha$-tocoferol; $\mathrm{TO}^{\bullet}$ - radical tocoferila; EGCG-OH - epigalocatequina (polifenol); EGCG-O•-radical do polifenol epigalocatequina; $A U$-ácido úrico; $A U \cdot$ - radical do ácido úrico; $G S H$ - glutationa; GS radical glutatiila reciclados por outros antioxidantes. Daí a importância da presença de várias classes de antioxidantes no plasma, na bicamada lipídica e no meio intracelular (Figura 9).

\section{Grupos vulneráveis à deficiência de antioxidantes}

Os idosos constituem um grupo vulnerável à desnutrição, devido à perda funcional da capacidade do pâncreas e intestino delgado, o que compromete a digestão e absorção de nutrientes ${ }^{86}$, que se tornam menos biodisponíveis. Associa-se ainda o declínio da função renal, que acarreta uma maior excreção de micronutrientes ${ }^{88}$. $\mathrm{O}$ decréscimo na sensibilidade dos sentidos sensoriais, como paladar e olfato, implica em menor consumo alimentar. Paralelamente ao aumento da expectativa de vida, há o aumento de doenças crônico-degenerativas não transmissíveis que, entre vários fatores, pode também resultar do decréscimo das defesas antioxidantes, consequiência da redução alimentar.

Desta forma, o estudo das necessidades dietéticas reais dos idosos bem como o desenvolvimento de suplementos que apresentem micronutrientes mais biodisponíveis são desejados. O desenvolvimento de alimentos novos ou métodos de preparo alternativos que realcem a absorção de nutrientes são também buscas interessantes.

Se os idosos representam grupo de risco devido à perda orgânica funcional, jovens e adultos que se submetem a dietas divulgadas em periódicos não científicos também podem desenvolver deficiências nutricionais. Amâncio e Chaud ${ }^{89}$ avaliaram dietas publicadas em revistas de grande circulação e verificaram que eram inadequadas em termos de macro e micronutrientes, sendo que a vitamina $\mathrm{E}$ apresentou cerca de $90 \%$ de inadequação. Além de dietas muito restritas, o uso de medicamentos inibidores de lipases e co-lipases do trato gastrointestinal leva à redução na absorção de gorduras, contribuindo para menor absorção de vitamina E e carotenóides, que são compostos lipossolúveis. Torna-se necessário o estudo do comprometimento do balanço redox no uso prolongado deste tipo de medicamento, bem como a divulgação do perigo que algumas dietas podem representar para a saúde.

Os atletas compõem uma classe em que o estresse oxidativo pode aumentar em conseqüência da aceleração de atividades metabólicas. Neste caso, o balanço redox pode ser rompido. Exercícios prolongados e intensos depletam antioxidantes, e se propõe que atletas tenham maior necessidade destes nutrientes. Nestes casos a suplementação dietética pode ser útil, inclusive aumentando o desempenho ${ }^{90}$. Portanto, deve-se estabelecer as verdadeiras necessidades destes indivíduos, verificar se o planejamento alimentar é capaz de suprir estas necessidades e, caso não seja, estabelecer doses seguras de suplementos.

Muitos pontos permanecem obscuros no estudo do papel de nutrientes como antioxidantes. As evidências mostram que alimentação diversificada rica em frutas e hortaliças beneficia a saúde; contudo, mais estudos devem ser realizados para se estabelecer o papel e a ação de nutrientes específicos na prevenção de doenças.

\section{AGRADECIMENTOS}

Ao incentivo da Dr ${ }^{\mathrm{a}}$ L. V. Modolo. Também, agradecem o suporte financeiro da FAPESP e do CNPq (Projeto Milênio Redoxoma).

\section{REFERÊNCIAS}

1. Augusto, O.; Radicais Livres: Bons, maus e naturais, Oficina de Textos: São Paulo, 2006

2. Halliwell, B.; Gutteridge, J. M. C.; Free Radicals in Biology and Medicine, $5^{\text {th }}$ ed., Claredon Press: Oxford, 1999.

3. Burdon, R. H.; Gill, V.; Alliangana, D.; Free Radical Res. 1996, 24, 81.

4. Lampe, J. W.; Am. J. Clin. Nutr. 1999, 70, 475s. 
5. Halliwell, B.; Adv. Pharmacol. 1997, 38, 3.

6. Augusto, O.; Hix, S.; Morais, M. S.; Vasquez-Vivar, J.; Ciência e Cultura 1995, $280,27$.

7. Djordjevic, V. B.; Int. Rev. Cytol. 2004, 237, 57.

8. Cochrane, C. G.; Mol. Aspects Med. 1991, 12 b, 137.

9. Gutteridge, J. M.; Clin. Chem. 1995, 41, 1829.

10. Linares, E.; Mortara, R. A.; Santos, C. X.; Yamada, A. T.; Augusto, O.; Free Radical Biol. Med. 2001, 30, 1234.

11. Fernandes D. C.; Medinas, D. B.; Alves, M. J.; Augusto, O.; Free Radical Biol. Med. 2005, 38, 189.

12. Lankin V. Z.; Lisina, M. O.; Arzamastseva, N. E.; Konovalova, G. G.; Nedosugova, V. V.; Kaminnyi, A. K.; Tikhase, A. K.; Aglev, F. T.; Kukharchuk, V. V.; Belenkov, Y. N.; Bull. Exp. Biol. Med. 2005, 140, 41.

13. Saito, A.; Maier, C. M.; Narasimham, P.; Nishi, T.; Song, Y. S.; Yu, F.; Liu, J.; Lee, Y. S.; Neto, C.; Kamada, H.; Doda, R. L.; Hseeh, L. B.; Hassid, B.; Kim, E. E.; Gonzalez, M.; Chan, P. H.; Mol. Neurobiol. 2005, 31, 105.

14. Tak, P. P.; Zvaifler, N. J.; Green, P. R.; Forestein, G. S.; Immunol. Today 2000, 21,78 .

15. Pravda, J.; World J. Gastroenterol. 2005, 11, 2371

16. Andican, G.; Gelisgen, R.; Unal, E.; Tortum, O. B.; Dervisoglu, S.; Karahasanoglu, T.; Burcak, G.; World J. Gastroenterol. 2005, 11, 2340.

17. Valko, M.; Rhodes, C. J.; Moncol, J.; Izakovic, M.; Mazur, M.; Chem.-Biol. Interact. 2006, 160, 1

18. Bondy, S. C.; Proc. Soc. Exp. Biol. Med. 1995, 208, 337.

19. De la Fuente, M.; Hanz, A.; Vallejo, M. C.; Antiox. Redox Signaling 2005, 7, 1356.

20. Santosa, S.; Jones, P. J. H.; CMAJ, Can. Med. Assoc. J. 2005, 173, 861.

21. Ramhman, I.; Curr. Drug Targets Inflamm. Allergy 2002, 1, 291.

22. Droge, W.; Adv. Exp. Med. Biol. 2003, 543, 191.

23. Demmig-Adams, B.; Adams, W. W.; Science 2002, 298, 2149.

24. Yeum, K. J.; Russell, R. M.; Krinsky, N. I.; Aldini, G.; Arch. Biochem. Biophys. 2004, 430, 97.

25. Munteanu, A.; Zingg, J. M.; Azzi, A.; J. Cell. Mol. Med. 2004, 8, 59.

26. Thomas, S. R.; Stocker, R.; Free Radical Biol. Med. 2000, 28, 1795.

27. Estrebauer, H.; Zollner, H.; Shaur, R. J.; Membrane Lipid Peroxidation, CRC Press: Boca Raton, 1990.

28. Loureiro, A. P. M.; Di Mascio, P.; Medeiros, M. H. G.; Quim. Nova 2002, 25, 777.

29. Kagan, V. E.; Serbinova, E. A.; Packer, L.; Arch. Biochem. Biophys. 1990, 280, 147.

30. Mukai, K.; Morimoto, H.; Kikushi, S.; Nagaoka, S.; Lipids 1993, $28,753$.

31. Terasawa, Y.; Ladha, Z.; Leonard, S. W.; Morrow, J. D.; Newland, D.; David, S.; Packer, L.; Traber, M. G.; Farese, R. V.; Proc. Natl. Acad. Sci. U. S. A 2000, 97, 13830 .

32. Halliwell, B.; Annu. Rev. Nutr. 1996, 16, 33.

33. Jessup, W.; Kritharides, L.; Stocker, R.; Biochem. Soc. Trans. 2004, 32, 134.

34. Devaraj, S.; Adams-Huet, B.; Fuller, C. J.; Jialal, I.; Arterioscler., Thromb., Vasc. Biol. 1997, 17, 2273.

35. Jialal, I.; Grundy, S. M.; Ann. N. Y. Acad. Sci. 1992, 669, 237.

36. Weinberg, R. B.; VanderWerken, B. S.; Anderson, R. A.; Stegner, J. E.; Thomas, M. J.; Arterioscler, Thromb., Vasc. Biol. 2001, 21, 1029.

37. Azzi, A.; Eur. J. Nutr. 2004, 43, 18 S.

38. Halliwell, B.; Mutat. Res. 2001, 475, 29.

39. Arrigoni, O.; De Tulio, M. C.; Biochim. Biophys. Acta 2002, 1569, 1.

40. Pauling, L.; Proc. Natl. Acad. Sci. U. S. A. 1970, 67, 1643.

41. Food and Nutrition Board, Institute of Medicine, National Academy of Sciences, Panel on Dietary Antioxidants and Related Compounds, Subcommittees on Upper Reference Levels of Nutrients and Interpretation and Uses of Dietary Reference Intakes, and the Standing Committee on the Scientific Evaluation of Dietary Reference Intakes. Dietary Reference Intakes for Vitamin C, Vitamin E, Selenium, and Carotenoids, National Academy Press: Washington, 2000.

42. Ames, B. N.; Mutat. Res. 2001, 475, 7.

43. Duarte, T. L.; Lunac, J.; Free Radical Res. 2005, 39, 671.

44. Pedro, M. A.; Gatty, R. M.; Augusto, O.; Quim. Nova 1993, 16, 370.

45. Halliwell, B.; Trends Biochem. Sci. 1999, 24, 255.

46. Herbert, V.; Jayatilleke, E.; J. Nutr. 1996, 126, 1213 S.

47. Green, M. H. L.; Lowe, J. E.; Waugh, A. P. W.; Aldridge, K. E.; Cole, J.; Arlett, C. F.; Mutat. Res. 1994, 316, 91; Duthie, S. J.; Ma, A.; Ross, M. A.; Collins, A. R.; Cancer Res. 1996, 56, 1291; Panayiotidis, M.; Collins, A. R.; Free Radical Res. 1997, 27, 533.
48. Podmore, I. D.; Griffiths, H. R.; Herbert, K. E.; Mistry, N.; Mistry, P.; Lunec, J.; Nature 1998, 392, 559; Cooke, M. S.; Evans, M.; Podmore, I. D.; Herbert, K. E.; Mistry, E. N.; Mistry, P.; Hickenbothan, P. T.; Hussieni, A.; Griffiths H. R.; FEBS Lett. 1998, 439, 363.

49. Welch, R. W.; Turley, E.; Sweetman, S, F.; Kennedy, G.; Collins, A. R.; Dunne, A.; Livingstone, M. B. E.; Mckenna, P. G.; Mckelvey-Martin, V. J.; Strain, J.; Nutr. Cancer 1999, 34, 167; Astley, S. B.; Elliott, R. M.; Archer, D. B.; Southon, S.; Br. J. Nutr. 2004, 91, 63

50. Gold, M. D.; Integr. Cancer Ther. 2003, 2, 158

51. Bernotti, S.; Seidman, E.; Sinnett, D.; Brunet, S.; Dionne, S.; Delvim, E.; Levy, E.; Am. J. Physiol. Gastrointest. Liver Physiol. 2003, 285, G898.

52. Catani, M. V.; Constanzo, A.; Savini, I.; Leviero, M.; De Laurenzi, V.; Wang, J. Y. J.; Melino, G.; Avigiliano, L.; Biochem. J. 2002, 364, 441.

53. Alcain, F. J.; Buron, M. I.; J. Bioenerg. Biomembr. 1994, 26, 393.

54. Lee, K. W.; Lee, H. J.; Surh, Y. J.; Lee, C.Y.; Am. J. Clin. Nutr. 2003, 78, 1074.

55. Fraser, P. D.; Bramley, P. M.; Prog. Lipid Res. 2004, 43, 228.

56. El-Agamey, A.; Lowe, G. M.; McGarvey, D. J.; Mortensen, A.; Phillip, D. M.; Truscott, T. G.; Young, A. J.; Arch. Biochem. Biophys. 2004, 430, 37.

57. Young, A.; Lowe, G. M.; Arch. Biochem. Biophys. 2001, 385, 20.

58. Tapiero, H.; Townsend, D. M.; Tew, K. D.; Biomed. Pharmacother. 2004, 58, 183.

59. Di Mascio, P.; Kaiser, S; Sies, H.; Arch. Biochem. Biophys. 1989, 274, 532

60. Mortensen, A.; Skibsted, L. H.; Truscott, T. G.; Arch. Biochem. Biophys. 2001, $385,13$.

61. Woodall, A. A.; Briton, G.; Jackson, M. J.; Biochim. Biophys. Acta 1997, 1336, 575.

62. Zhang, P.; Omaye, S. T.; J. Nutr. Biochem. 2001, 12, 38.

63. Rowe, M. P.; Lancet 1996, 347, 249.

64. Malila, N.; Taylor, R. P.; Virtanen, M. J.; Korhonen, J.; Huttunen, J. K.; Albanes, D.; Virtamo, J.; Cancer Causes Control 2002, 13, 617.

65. Halliwell, B.; Annu. Rev. Nutr. 1996, 16, 33.

66. Manach, C., Scalbert, A.; Morand, C.; Rémésy, C.; Jimenez, L.; Am. J. Clin. Nutr. 2004, 79, 727

67. Duthie, G. G.; Nutr. Res. Rev. 2000, 13, 69 .

68. Sun, A. Y.; Simonyi, A.; Sun, G. Y.; Free Radical Biol. Med. 2002, 32, 314

69. McKay, D. L.; Blumberg, J. B.; J. Am. Coll. Nutr. 2002, 21, 1.

70. Klatsky, A. L.; Sci. Am. 2003, 288, 63.

71. Dreosti, I. E.; Nutrition 2000, 16, 692

72. Visioli, F.; Poli, A.; Gall, C.; Med. Res. Rev. 2002, 22, 65

73. Ross, J. A.; Kasum, C. M.; Annu. Rev. Nutr. 2002, 22, 19.

74. Tuck, L. K.; Hayball, P. J.; J. Nutr. Biochem. 2002, 13, 636; Higdon, J. V.; Frei, B.; Crit. Rev. Food Sci. Nutr. 2003, 89,143; Frankel, E. N.; Kanner, J.; German, J. B.; Parks, E.; Kinsella, J.; Lancet 1993, 341, 454

75. Williamson, G.; Manach, C.; Am. J. Clin. Nutr. 2005, 81, 243S.

76. Key, T.; Oakes, S.; Davey, G.; Moore, J.; Edmond, L. M.; McLoone, U. J.; Thurnham, D. I.; Cancer Epidemiol. Biomarkers Prev. 1996, 5, 811.

77. Szeto, Y. T.; Kwork, T. C. Y.; Benzie, I. F.; Nutrition 2004, 20, 863.

78. Choi, S. W.; Benzie, I. F.; Collins, A. R.; Hannigan, B. M.; Strain, J.; J. Mutat. Res. 2004, 551, 109.

79. Levine, M.; Conrycantilena, C.; Wang, Y. H.; Welch, R. W.; Washko, P. W.; Dhariwal, K. R.; Park, J. B.; Lazarev, A.; Graumlich, J. F.; King, J.; Cantilena, L. R.; Proc. Natl. Acad. Sci. U. S. A. 1996, 93,704.

80. Azzi, A.; Ricciarelli, R.; Zingg, J .M.; FEBS Lett. 2002, 519, 8.

81. Faulks, R. M.; Southon, S.; Biochim. Biophys. Acta. 2005, 1740, 95.

82. Halliwell, B.; Lancet 2000, 355, 1179.

83. Fenech, M.; Food Chem. Toxicol. 2002, 40, 1113

84. Hercberg, S.; Galan, P.; Preziosi, P.; Bertrais, S.; Mennen, L.; Malvy, D.; Roussel, A. F.; Serge, A. B.; Arch. Intern. Med. 2004, 164, 2335.

85. Knoops, K. T.; de Groot, L. C.; Kromhout, D.; Perrin, A. E.; Moreiras-Varela, O.; Menotti, A.; van Staveren, W. A.; JAMA, J. Am. Med. Assoc. 2004, 292, 1433.

86. World Cancer Research Fund and the American Institute for Cancer research; Food, Nutrition and the prevention of cancer: A global perspective. American Institute for cancer Research: Washington, 1997.

87. Ritz, P.; Eur. J. Clin. Nutr. 2000, 54, $21 \mathrm{~S}$.

88. Russell, R. M.; J. Nutr. 2001, 131, 1359 S.

89. Amâncio, O. M. S.; Chaud, D. M. A.; Cad. Saúde Pública 2004, 20, 1219.

90. Packer, L.; J. Sports Sci. 1997, 15, 353. 